\title{
Perception of Asthma Symptoms as Assessed on the Visual Analog Scale in Subjects With Asthma: A Real-Life Study
}

\author{
Giorgio Ciprandi MD, Irene Schiavetti, Valentina Sorbello PhD, and Fabio LM Ricciardolo MD
}

\begin{abstract}
BACKGROUND: The perception of symptoms is a cornerstone in asthma management, but studies concerning this aspect provide conflicting evidence. The visual analog scale has been proposed as a useful tool for assessing perception of respiratory symptoms. The present study investigated whether visual analog scale assessment of perception of asthma symptoms was correlated to lung function or clinical features. METHODS: This cross-sectional study enrolled 388 subjects with asthma (159 males; mean age $39.7 \mathrm{y}$ ). Perception of asthma symptoms was assessed by the visual analog scale; lung function was measured by spirometry. Asthma control was evaluated by the asthma control test. Anxiety and depression were evaluated on the Hospital Anxiety and Depression Scale questionnaire. RESULTS: Asthma was well controlled in 46.6\% of subjects. Asthma symptoms in the prior month were reported by $59 \%$ of subjects; asthma signs were detected in $\mathbf{7 . 2 \%}$. The visual analog scale score was moderately correlated to $\operatorname{FEV}_{1}(r=0.43)$. Subjects with bronchial obstruction had lower visual analog scale values than those without $(P<.001)$. A visual analog scale score of 6 was a reliable cutoff point to discriminate subjects with bronchial obstruction (area under the curve $=0.71$ at receiver operating characteristic curve; odds ratio $[\mathrm{OR}]=7.58)$. Reported asthma symptoms $(O R=4.83)$, asthma signs $(O R=8.36)$, and anxiety $(O R=1.14)$ were predictive of a visual analog scale score of $<6$. CONCLUSIONS: This real-life study found that assessment of asthma symptoms by the visual analog scale might be a reliable tool in managing patients with asthma. Key words: asthma; visual analog scale; asthma symptoms; lung function; bronchial obstruction. [Respir Care 2016;61(1):23-29. (C) 2016 Daedalus Enterprises]
\end{abstract}

\section{Introduction}

Asthma is a chronic disorder characterized by episodic and variable bronchial air flow limitation that may cause the appearance of symptoms and signs as defined by the Global Initiative for Asthma guidelines. ${ }^{1}$ Asthma control is currently considered the principal goal of management strategies; the degree of control serves to classify asthma

\footnotetext{
Dr Ciprandi is affiliated with the Department of Medicine, IRCCSAzienda Ospedaliera Universitaria San Martino, Genoa, Italy. Ms Schiavetti is affiliated with the Health Science Department, University of Genoa, Genoa, Italy. Drs Sorbello and Ricciardolo are affiliated with the Division of Respiratory Disease, Department of Clinical and Biological Sciences, University of Turin, Turin, Italy.
}

The authors have disclosed no conflicts of interest.

Correspondence: Giorgio Ciprandi MD. E-mail gio.cip@libero.it.

DOI: $10.4187 /$ respcare.04171 severity. The definition of well-controlled asthma, proposed by the Global Initiative for Asthma guidelines, includes: daytime asthma symptoms not more than twice per week, no night waking, reliever use not more than twice per week, and no activity limitation in the past 4 weeks.

Most patients with asthma are managed by their general practitioner, who bases treatment decisions solely on reported symptoms and clinical examination. Typical asthma symptoms include breathlessness, chest tightness, wheezing, cough, and exercise-induced symptoms. Inaccurate perception of asthma severity often delays asthma diagnosis and treatment, worsening both morbidity and mortality. ${ }^{2}$ Precise symptom perception is an important component in appropriate self-management of asthma, since recognition of asthma severity enables the patient to make appropriate changes in activity level, to alter the physical environment, and to modify the medical regimen in a timely fashion. ${ }^{3}$ However, there may be a discrepancy between the patient's perception of asthma symptoms and objective measures of lung function. ${ }^{4,5} \mathrm{~A}$ number of tools exist to 
evaluate symptom perception; of these, the visual analog scale has been used successfully in several studies. The validity of the visual analog scale to assess the sensation of breathlessness has been evaluated in both experimental and clinical studies. ${ }^{6,7}$ The visual analog scale was found to be reliable in assessing symptom severity, as compared with lung function testing: bronchial air flow obstruction is the hallmark of asthma and may readily be measured by spirometry. Although $\mathrm{FEV}_{1}$ is considered the accepted standard to diagnose and manage asthma, the forced expiratory flow between 25 and $75 \%$ of vital capacity $\left(\mathrm{FEF}_{25-75 \%}\right)$ may be a more sensitive indicator of chronic air flow obstruction in patients with mild asthma and normal $\mathrm{FEV}_{1}{ }^{8-10}$

Conversely, physical signs may be inadequate for detecting bronchial obstruction with certainty, and considerable airway obstruction may be present despite a normal clinical examination. ${ }^{11}$ Further, spirometry is not regularly performed by general practitioners treating patients with asthma, as reported by the Asthma Insights and Reality Europe study ${ }^{12}$ : only $29 \%$ of subjects with asthma had undergone lung function testing in the past year, and $>50 \%$ of subjects with asthma had never undergone spirometry. Thus, many patients with asthma are managed without going to specialized centers and without lung function assessment.

In this context, it was first shown that visual analog scale assessment of asthma symptoms may be useful in children with asthma. ${ }^{13} \mathrm{~A}$ subsequent cross-sectional study provided evidence that visual analog scale assessment of breathlessness perception could reliably evaluate symptom severity as compared with lung function measurement in a large cohort of children with a clinical diagnosis of asthma. ${ }^{14}$ It was hypothesized that the patient's perception of asthma symptoms, expressed through a visual analog scale score, might correlate with the degree of bronchial obstruction as measured by the $\mathrm{FEV}_{1}$. The present study aimed to test this hypothesis in an adult cohort of subjects with asthma in a real-life setting.

\section{Methods}

\section{Subjects}

This cross-sectional study enrolled 388 subjects suffering from asthma ( 159 males; mean age $39.7 \mathrm{y}$ ). They were out-patients who had been referred to an asthma or allergy clinic for specialist examination and were recruited consecutively. The examination included medical history, clinical examination, lung function testing, Hospital Anxiety and Depression Scale (HADS) and asthma control test questionnaires, and assessment of the degree of asthma control. The hospital review board approved the study

\section{QUICK LOOK}

\section{Current knowledge}

Asthma is a chronic disorder characterized by episodic and variable bronchial air flow limitation that may cause the appearance of symptoms and signs, as defined by the Global Initiative for Asthma guidelines. Asthma control is currently considered the principal goal of management strategies; the degree of control serves to classify asthma severity.

\section{What this paper contributes to our knowledge}

In a group of out-patient subjects with asthma, a visual analog scale score for asthma symptoms of $<6$ reflected a 7 times greater likelihood of bronchial obstruction (eg, $\mathrm{FEV}_{1}<80 \%$ of predicted) than a score of $\geq 6$. Visual analog scale scoring appeared to be a reliable tool to assess subjects' perceptions of asthma symptoms.

procedure; written informed consent was obtained from each subject.

\section{Study Design and Setting}

The inclusion criterion was a documented asthma diagnosis, made by a pulmonary specialist or an allergist and based on a history of intermittent wheezing, breathlessness, cough, and chest tightness, in combination with reversibility to bronchodilators and/or bronchial hyper-responsiveness to methacholine. Exclusion criteria were: a history of lung disease other than asthma; coronary artery disease; congestive heart failure or cor pulmonale; recent asthma exacerbation; and the presence of acute (in the last 4 weeks) or chronic upper and/or lower respiratory infections. Subjects discontinued use of long-acting bronchodilators for $12 \mathrm{~h}$ before measurement of lung function.

For all subjects, the following variables were recorded: age, sex, co-presence of rhinitis, reported asthma and rhinitis symptoms in the last month, presence of asthma signs (in particular wheezing) at physical examination, FVC, $\mathrm{FEV}_{1}, \mathrm{FEV}_{1} / \mathrm{FVC}, \mathrm{FEF}_{25-75 \%}$, degree of asthma control, visual analog scale, HADS, and asthma control test.

\section{Functional Assessment}

Spirometry was performed using a computer-assisted spirometer (Pulmolab 435-Spiro 235, Pulmolab, Morgan, United Kingdom; predictive values ECCS, 1993), with optoelectronic whirl flow meter. This spirometer fulfills the American Thoracic Society/European Respiratory So- 
ciety standards as per the guidelines, and the test was performed as described by the European Respiratory Society. ${ }^{15,16}$

\section{Asthma Control}

Asthma control was assessed following the most recent Global Initiative for Asthma guidelines: subjects were classified as having well-controlled, partly controlled, or uncontrolled asthma.

\section{Asthma Control Test}

The asthma control test questionnaire comprised 5 questions, each with 5 possible responses, and aimed to explore the subject's perception of his/her asthma control. ${ }^{17}$ The resulting score was in the range $0-25$, where 25 indicates optimal asthma control.

\section{Rhinitis}

Rhinitis was diagnosed if there was a history of typical nasal symptoms, such as itching, sneezing, watery rhinorrhoea, and nasal obstruction. If symptom occurrence was consistent with exposure to one or more sensitizing allergens, a diagnosis of allergic rhinitis was formulated.

\section{Visual Analog Scale}

The visual analog scale evaluation system comprised a $10 \mathrm{~cm}$ long segment, upon which the subject was asked to indicate his/her actual perception of asthma symptoms by marking a point along the segment. ${ }^{18}$ In this study, 0 corresponded to the most severe symptoms, whereas 10 corresponded to optimal symptom-free breathing. The segment was without interval markers.

\section{HADS Questionnaire}

Participants were asked to fill out the self-reported HADS. ${ }^{19}$ The HADS is a 14-item scale that generates ordinal data. Seven of the items relate to anxiety, and 7 relate to depression. Each item is rated on a 4-point scale: 0 , not at all; 1 , sometimes; 2 , often; 3 , all of the time. This gives maximum subscale scores of 21 for anxiety and 21 for depression. HADS gives clinically meaningful results when used as a psychological screening tool in clinical group comparisons and has been found to correlate with several aspects of patient disease and quality of life. ${ }^{20} \mathrm{In}$ the validation of the questionnaire, a score of $>7$ in the 2 subscales has been found to discriminate non-cases from suspected cases. ${ }^{19}$

\section{Statistical Analysis}

Possible correlations between visual analog scale score and any other clinical or personal variable were assessed using non-parametric tests. In particular, differences in visual analog scale score between patients with bronchial obstruction $\left(\mathrm{FEV}_{1}<80 \%\right.$ of predicted value) and those without bronchial obstruction $\left(\mathrm{FEV}_{1} \geq 80 \%\right.$ of predicted value) were evaluated with the Mann-Whitney test.

The non-parametric Spearman rank correlation coefficient was applied to assess the degree of correlation between visual analog scale score and measurements of lung function; correlation coefficients were classified as: $\geq 0.8=$ very strong; $0.6-0.79=$ strong; $0.4-$ $0.59=$ moderate; $0.2-0.39=$ weak; and $<0.2=$ very weak. $^{21}$

A receiver operating characteristic curve, a graphical plot with values of sensitivity (reported on the y axis) and specificity (on the $\mathrm{x}$ axis), was applied to assess the accuracy of the visual analog scale in predicting bronchial obstruction. For each receiver operating characteristic curve, the area under the curve with the corresponding 95\% CI was plotted, and the best cutoff point for visual analog scale scores, which provided both the highest sensitivity and the highest specificity, was determined.

Correlations between the visual analog scale cutoff point and other clinical variables were determined using the Fisher exact test, the chi-square test, and the Mann-Whitney test. Statistically significant variables at univariate analysis $(P<.10)$ were fitted in a binary logistic regression model.

A 2-tailed $P$ value of $<.05$ was considered significant. All statistical analyses were performed using the SPSS 20.0 (SPSS, Chicago, Illinois).

\section{Results}

The personal and clinical characteristics of the enrolled subjects are reported in Table 1; the mean age was $39.7 \mathrm{y}$, $41 \%$ of the study group were males, and approximately two thirds of subjects suffered from rhinitis. Mean lung function parameters were normal; at least one asthma symptom was reported by $59 \%$ of subjects, and asthma signs were present in $7.2 \%$ of subjects. With regard to asthma control, $13 \%$ of subjects were found to be uncontrolled, $40.4 \%$ partly controlled, and $46.6 \%$ well-controlled. The mean asthma control test value was 19.8 ; the visual analog scale score for breathlessness was 7.2.

A weak, although significant, positive correlation was found between visual analog scale score and percent-ofpredicted $\mathrm{FEV}_{1} / \mathrm{FVC}(\mathrm{r}=0.13, P=.01)$. A moderately significant positive correlation was found between visual analog scale score and percent-of-predicted $\mathrm{FEV}_{1}(\mathrm{r}=0.43$, $P=.001)$ (Fig. 1A). The visual analog scale was also weakly correlated with percent-of-predicted FVC $(\mathrm{r}=0.38$, 
Table 1. Demographic and Clinical Characteristics in Subjects

\begin{tabular}{lcc}
\hline \hline & Mean $\pm \mathrm{SD}$ & $n(\%)$ \\
\hline Age, y & $39.7 \pm 16.2$ & $\mathrm{NA}$ \\
Males & $\mathrm{NA}$ & $159(41.0)$ \\
Body mass index & $25.0 \pm 6.0$ & $\mathrm{NA}$ \\
Rhinitis & $\mathrm{NA}$ & $254(65.5)$ \\
$\mathrm{FVC}, \%$ predicted & $101.9 \pm 17.7$ & $\mathrm{NA}$ \\
$\mathrm{FEV}_{1}, \%$ predicted & $93.4 \pm 19.9$ & $\mathrm{NA}$ \\
$\mathrm{FEV}_{1} / \mathrm{FVC}$ & $81.8 \pm 11.9$ & $\mathrm{NA}$ \\
$\mathrm{FEF}_{25-75 \%} \%$ predicted & $72.8 \pm 28.8$ & $\mathrm{NA}$ \\
Asthma symptoms $_{\text {Asthma signs }}$ & $\mathrm{NA}$ & $229(59)$ \\
Rhinitis symptoms $_{\text {Asthma control }}$ & $\mathrm{NA}$ & $28(7.2)$ \\
Uncontrolled $_{\text {Partly controlled }}$ & & $201(51.8)$ \\
Well-controlled $_{\text {Asthma control test }}$ & $\mathrm{NA}$ & $51(13)$ \\
Visual analog scale & $\mathrm{NA}$ & $157(40.4)$ \\
& $\mathrm{NA}$ & $180(46.6)$ \\
\hline NA $=$ not applicable & $19.8 \pm 4.5$ & $\mathrm{NA}$ \\
FEF & & $\mathrm{NA}-75 \%=$ forced expiratory flow during the middle half of the FVC maneuver \\
\hline
\end{tabular}

$P<.001)$ and with percent-of-predicted $\mathrm{FEF}_{25-75 \%}$ $(\mathrm{r}=0.33, P<.001)$, as reported in Figure 1B.

A statistically significant difference in visual analog scale score was found between subjects with and those without bronchial obstruction $(P<.001)$, with a lower score in the former (median 6.0, interquartile range 4.0-7.0) than in the latter (median 8.0, interquartile range 6.0-9.0) (Fig. 2).

Receiver operating characteristic curve analysis revealed an optimal predictive cutoff value of the visual analog scale for detecting bronchial obstruction (ie, $\mathrm{FEV}_{1}<80 \%$ of predicted). It was set at 6.0 , with sensitivity $88.60 \%$, specificity $49.37 \%$, diagnostic accuracy $80.57 \%$, and area under the receiver operating characteristic curve 0.71 (95\% CI: $0.64-0.79)(P<.001)$. The positive likelihood ratio was 1.75 , and the negative likelihood ratio was 0.23 , with a statistically significant $(P<.001)$ diagnostic odds ratio (OR) of 7.58 (95\% CI: 4.31-13.32). In brief, this means that subjects reporting visual analog scale scores of $<6$ were almost 8 times more likely to have bronchial obstruction than those reporting visual analog scale scores of $\geq 6$ (Fig. 3). Figure 3 shows the percentage frequency distribution of visual analog scale scores in subjects with and without bronchial obstruction.

Once the optimal visual analog scale score cutoff point was set at 6 , the subjects were subdivided in 2 subgroups: subjects with a visual analog scale score of $\geq 6$ and subjects with visual analog scale score of $<6$ (Table 2). Subjects with a visual analog scale score of $<6$ had all spirometric parameters significantly $(P<.001$ for all $)$ lower than subjects with a visual analog scale score of $\geq 6$; less frequently had rhinitis $(P<.001)$; more frequently had asthma signs at clinical examination; and more frequently reported asthma symptoms in the past month than subjects with a visual analog scale score of $\geq 6$. In addition, subjects with a visual analog scale score of $<6$ more frequently had uncontrolled asthma $(P<.001)$, had lower asthma control test values $(P<.001)$, and had higher HADS-A (HADS anxiety) and HADS-D (HADS depression) scores $(P<.02$ and $P<.02$, respectively) than subjects with a visual analog scale score of $\geq 6$. However, mean HADS-D score was also in the normal range in subjects with a visual analog scale of $<6$, whereas mean HADS-A score was impaired, defined as $>7$, in subjects with a visual analog scale of $<6$.

Considering the visual analog scale cutoff of 6 , the variables found by multivariate analysis to be related to it were asthma signs and symptoms and HADS-A score. In particular, subjects with reported symptoms and subjects with asthma signs were almost 5 and 8 times more likely, respectively, to have a visual analog scale score of $\leq 6$, compared with subjects without these characteristics $(\mathrm{OR}=$ $4.83,95 \%$ CI: $1.63-14.34, P=.005$; OR $=8.36,95 \%$ CI: 2.22-31.43, $P=.002$, respectively). Moreover, subjects with higher values of HADS-A were more likely to have lower visual analog scale scores $(\mathrm{OR}=1.14,95 \% \mathrm{CI}$ : 1.01-1.28, $P=.04$ (Table 2).

\section{Discussion}

Although a number of studies have examined subjects' perception of asthma symptoms, most were conducted on subjects having symptoms induced experimentally by bronchoconstriction stimuli (eg, methacholine, histamine, or exercise) or only during periods of asthma exacerbation. These studies may thus be considered to have been conducted in experimental settings. A recent study investigated the relationship between lung function and symptom perception in subjects with asthma, reporting a weak association; however, this study was conducted on a restricted cohort, and bronchial obstruction was exerciseand methacholine-induced. ${ }^{22}$ An earlier large real-life study, conducted in pediatric subjects with asthma, provided evidence that the visual analog scale score for breathlessness could predict bronchial obstruction reasonably well. ${ }^{14}$ The present study was designed to confirm those data in a large real-life population of adult subjects with asthma.

The findings show that most subjects had controlled asthma and that lung function was normal in many subjects. Most subjects perceived their symptoms as moderate. Obviously, the perception of impaired respiration mainly depends on the severity of the asthma and partially also on lung function. In this connection, there was a significant correlation between perceived respiratory symptoms and lung function, especially applying to $\mathrm{FEV}_{1}$. Subjects with bronchial obstruction, namely those with 

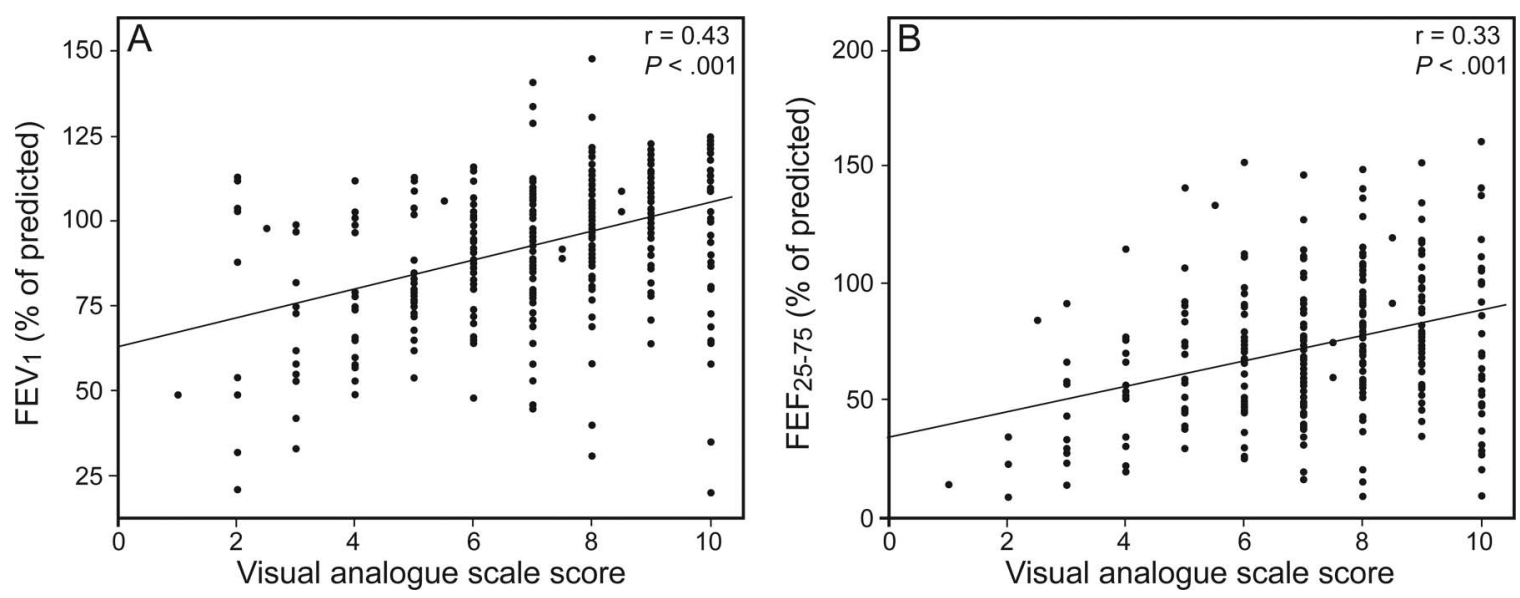

Fig. 1. Correlation between visual analog scale score and pulmonary function.

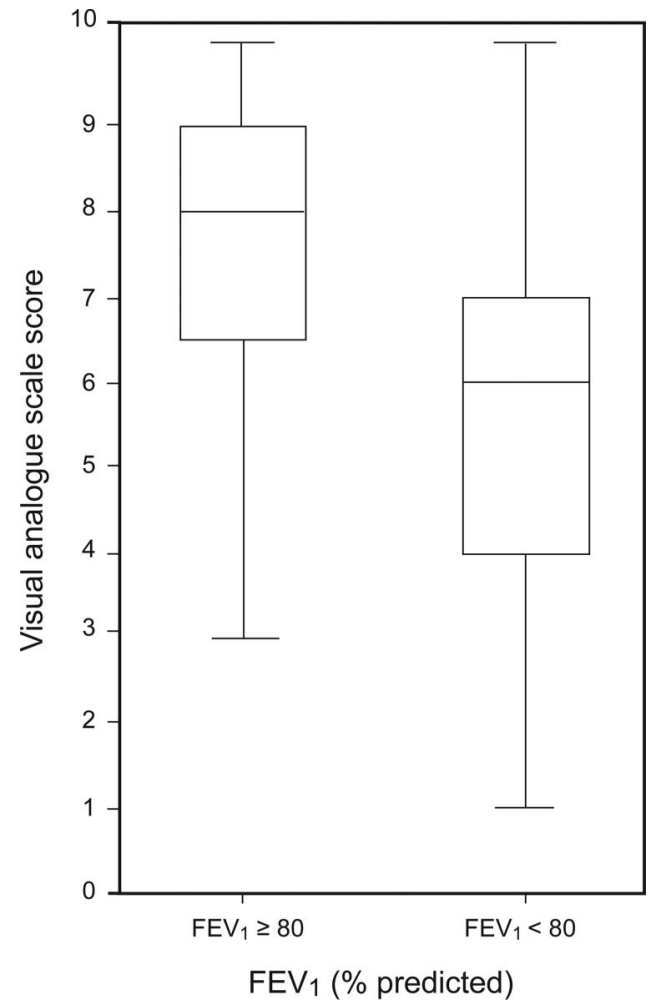

Fig. 2. Comparison between the median visual analogue scale scores between subjects with $\mathrm{FEV}_{1}$ values $\geq 80 \%$ or $<80 \%$ of predicted. Boxes show interquartile range, whiskers denote $\pm S D$, and the center lines show the median.

$\mathrm{FEV}_{1}<80 \%$ of predicted, were found to have visual analog scale scores markedly lower than those without bronchial obstruction. A cutoff point for visual analog scale scores of 6 satisfactorily discriminated subjects with bronchial obstruction; thus, the simple assessment of asthma symptoms by the visual analog scale could offer some preliminary information concerning the bronchial air flow. This finding confirms those of the above-mentioned pediatric study. ${ }^{15}$
The present results are also consistent with findings reported by an epidemiological survey conducted on 29,518 subjects with asthma, ${ }^{23}$ which found that visual analog scale measurement of asthma severity predicted the degree of asthma control, the authors concluding that the visual analog scale score could be a simple guide in clinical situations requiring daily or regular evaluation of asthma control. The present data also suggest that the visual analog scale might be a simple predictor of lung function because there was a statistically significant correlation with both $\mathrm{FEV}_{1}$ and $\mathrm{FEF}_{25-75 \%}$.

It should be stressed that this study also confirms the earlier pediatric study, ${ }^{14}$ since both studies suggest that visual analog scale scores of $<6$ point to suspected bronchial air flow limitation. This outcome is of clinical relevance, since the simple assessment of the visual analog scale, which can be administered in any setting, may give indications of suspected bronchial obstruction.

Interestingly, subjects with higher anxiety tended to report lower visual analog scale scores. This is consistent with a recent study that found a close correlation between respiratory symptoms and psychological status, particularly anxiety. ${ }^{24}$ It is known that there is a correlation between asthma and some mental disorders, chiefly those related to anxiety and depression ${ }^{25,26}$; elevated comorbidity with anxiety and depression has been reported, and several theories have been advanced. A cognitive theory connects the long-term experience of respiratory symptoms with the generation of fear. ${ }^{27}$ Biological theories consider hypoxia and hypercapnia as factors sensitizing the neural circuits that control fear responses. ${ }^{28}$ Psychological theories emphasize the role played by stress, which affects respiration. ${ }^{29}$ The current study found that subjects with asthma with a perception of impaired breathing (ie, visual analog scale score of $<6$ ) also had above-normal anxiety scores: this is consistent with the hypothesis that anxiety may negatively affect asthma. ${ }^{30}$ 

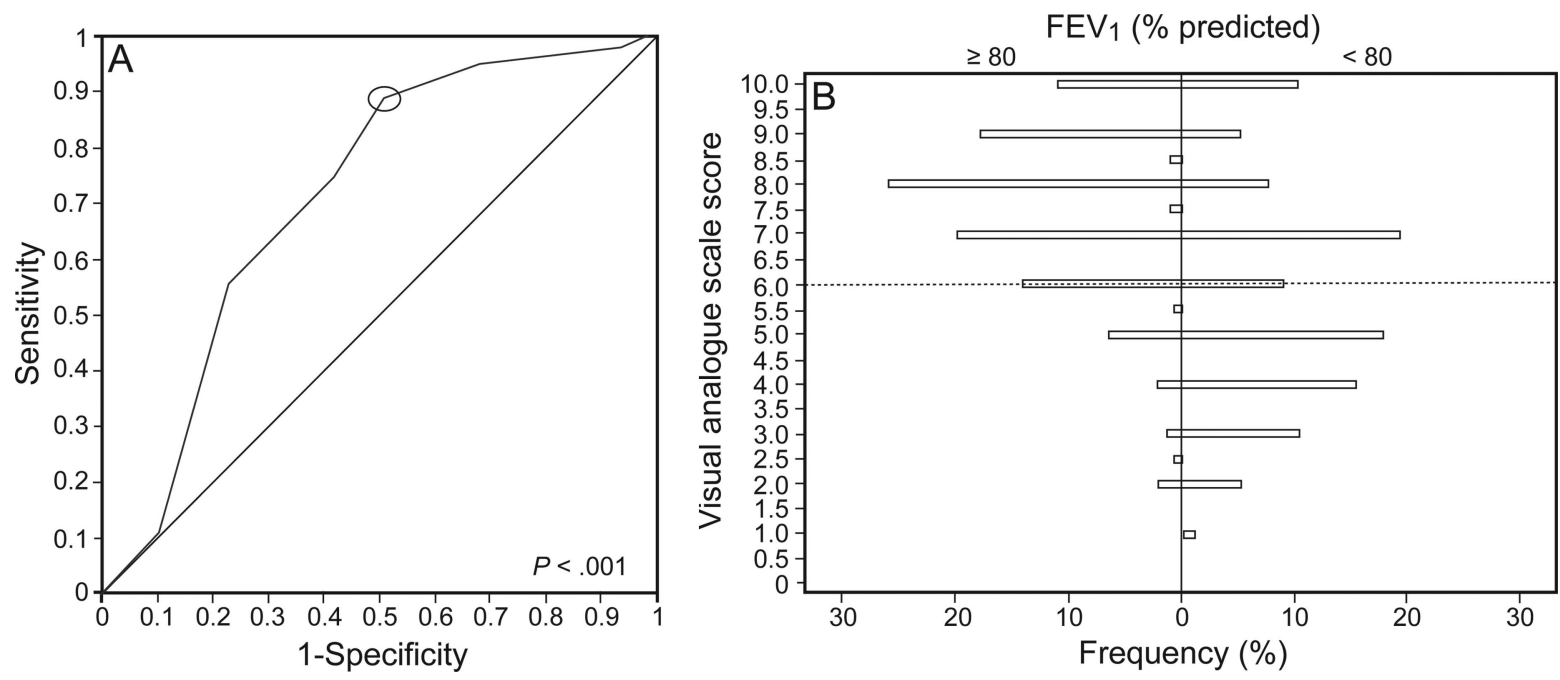

Fig. 3. A: Optimal cutoff point (circled) at which visual analog scale score categorizes subjects with versus those without bronchial obstruction. Area under the curve $=0.71(\mathrm{Cl}: 0.64-0.79)$. B: Frequency of distribution of visual analogue scale scores in subjects with and without bronchial obstruction.

Table 2. Relationship Between Visual Analog Scale Score and Other Characteristics Assessed by Univariate and Multivariate Analysis

\begin{tabular}{|c|c|c|c|c|c|c|}
\hline & \multicolumn{4}{|c|}{ Visual Analog Scale } & \multirow{3}{*}{$P$} & \multirow{3}{*}{$P$ Multivariate } \\
\hline & \multicolumn{2}{|c|}{$\geq 6$} & \multicolumn{2}{|c|}{$<6$} & & \\
\hline & Mean \pm SD & $n(\%)$ & Mean \pm SD & $n(\%)$ & & \\
\hline Age & $39.4 \pm 16.1$ & NA & $41.7 \pm 16.4$ & NA & .49 & NA \\
\hline Males (relative to females) & NA & 133 & NA & 26 & .32 & NA \\
\hline Body mass index & $24.8 \pm 5.0$ & NA & $26.0 \pm 9.4$ & NA & .84 & NA \\
\hline Rhinitis & NA & $220(68.3)$ & NA & $34(51.5)$ & $<.001$ & NA \\
\hline FVC, $\%$ predicted & $104.3 \pm 16.6$ & NA & $91.5 \pm 18.3$ & NA & $<.001$ & NA \\
\hline $\mathrm{FEV}_{1}, \%$ predicted & $96.9 \pm 17.8$ & NA & $79.0 \pm 21.9$ & NA & $<.001$ & NA \\
\hline $\mathrm{FEV}_{1} / \mathrm{FVC}$ & $82.6 \pm 10.8$ & NA & $78.5 \pm 15.4$ & NA & $<.001$ & NA \\
\hline $\mathrm{FEF}_{25-75 \%}, \%$ predicted & $76.5 \pm 27.4$ & NA & $54.2 \pm 28.7$ & NA & $<.001$ & NA \\
\hline Asthma signs & NA & $14(4.3)$ & NA & $14(21.2)$ & $<.001$ & $\begin{array}{l}P=.002 ; \mathrm{OR}=8.36 \\
\quad(\mathrm{CI}: 2.22-31.43)\end{array}$ \\
\hline Asthma symptoms & NA & $167(51.9)$ & NA & $62(94)$ & $<.001$ & $\begin{array}{c}P=.005 ; \mathrm{OR}=4.83 \\
\quad(\mathrm{CI}: 1.63-14.34)\end{array}$ \\
\hline Rhinitis symptoms & NA & $156(48.4)$ & NA & $45(68.2)$ & .14 & \\
\hline \multicolumn{7}{|l|}{ Asthma control } \\
\hline Uncontrolled & NA & $30(9.3)$ & NA & $21(31.8)$ & $<.001$ & \\
\hline Partly controlled & NA & $127(39.4)$ & NA & $30(45.5)$ & $<.001$ & \\
\hline Well-controlled & NA & $165(51.3)$ & NA & $15(22.7)$ & $<.001$ & \\
\hline Asthma control test & $20.4 \pm 4.2$ & NA & $17.3 \pm 4.8$ & NA & $<.001$ & \\
\hline HADS-A & $6.1 \pm 3.9$ & NA & $7.9 \pm 4.6$ & NA & .02 & $\begin{array}{c}P=.04 ; \mathrm{OR}=1.14 \\
\quad(\mathrm{CI}: 1.01-1.28)\end{array}$ \\
\hline HADS-D & $3.6 \pm 2.7$ & NA & $5.0 \pm 3.7$ & NA & .02 & \\
\hline \multicolumn{7}{|c|}{$\begin{array}{l}\mathrm{NA}=\text { not applicable } \\
\mathrm{FEF}_{25-75 \%}=\text { forced expiratory flow during the middle half of the FVC maneuver } \\
\mathrm{OR}=\text { odds ratio } \\
\text { HADS-A = Hospital Anxiety and Depression Scale anxiety } \\
\text { HADS-D = Hospital Anxiety and Depression Scale depression }\end{array}$} \\
\hline
\end{tabular}

In addition, subjects with low visual analog scale scores had lower asthma control test values than did those with high visual analog scale scores. This finding could rein- force the relevance of visual analog scale assessment, since well-controlled asthma is associated with the perception of good breathing; a study is ongoing to investigate this issue. 
More interestingly from the clinical standpoint, the presence of asthma signs, namely wheezing, together with any asthma symptom during the past 4 weeks were relevant predictors for low visual analog scale values. This finding reinforces the concept that clinical assessment remains a cornerstone in the management of patients with asthma. Conversely, this real-life study has some limitations: few of the subjects had overt bronchial obstruction, and the study was cross-sectional. It is thus to be hoped that further studies will address these issues.

\section{Conclusions}

The principal finding of the present real-life study is that a subject with a visual analog scale score for asthma symptoms of $\leq 6$ has a 7 times greater likelihood of bronchial obstruction (eg, $\mathrm{FEV}_{1}<80 \%$ of predicted) than a subject with a visual analog scale score of $>6$. It may thus be concluded that visual analog scale scoring appears to be a reliable tool to assess patients' perception of asthma symptoms.

\section{REFERENCES}

1. Global Initiative for Asthma (GINA). GINA Report, Global Strategy for Asthma Management and Prevention. http://www.ginasthma.com/ guidelineitem.asp??11 $=2 \& 12=1 \&$ intId $=1561$. Accessed January 31, 2015.

2. Mendoza GR. Peak flow monitoring. J Asthma 1991;28(3):161-177.

3. Yoos HL, McMullen A. Symptom perception and evaluation in childhood asthma. Nurs Res 1999;48(1):2-8.

4. McFadden ER Jr., Kiser R, DeGroot WJ. Acute bronchial asthma: relations between clinical and physiologic manifestations. N Engl J Med 1973;288(5):221-225.

5. Fritz GK, Klein RB, Overholser JC. Accuracy of symptom perception in childhood asthma. J Dev Behav Pediatr 1990;11(2):69-72.

6. Janson-Bjerklie S, Carrieri VK, Hudes M. The sensations of pulmonary dyspnea. Nurs Res 1986;35(3):154-159.

7. Wilson RC, Jones PW. A comparison of the visual analogue scale and modified Borg scale for the measurement of dyspnea during exercise. Clin Sci 1989;76(3):277-282.

8. Simon MR, Chinchilli VM, Phillips BR, Sorkness CA, Lemanske RF $\mathrm{Jr}$, Szefler SJ, et al. Forced expiratory flow between $25 \%$ and $75 \%$ of vital capacity and $\mathrm{FEV}_{1}$ /forced vital capacity ratio in relation to clinical and physiological parameters in asthmatic children with normal FEV ${ }_{1}$ values. J Allergy Clin Immunol 2010;126(3):527-534.e1-8.

9. Ciprandi G, Cirillo I, Pasotti F, Ricciardolo F. $\mathrm{FEF}_{25-75}$ :a marker for small airways and asthma control. Ann Allergy Asthma Immunol 2013;111(3):233.

10. Ciprandi G, Tosca MA, Capasso M. $\mathrm{FEF}_{25-75}$ might be a predictive factor for bronchial hyperreactivity in children with allergic rhinitis, asthma, or both. Allergy Asthma Proc 2011;32(5):e22-e28.
11. Shim CS, Williams MH Jr. Evaluation of the severity of asthma: patients versus physicians. Am J Med 1980;68(1):11-13.

12. Rabe KF, Vermeire PA, Soriano JB, Maier WC. Clinical management of asthma in 1999: the Asthma Insights and Reality Europe (AIRE) study. Eur Respir J 2000;16(5):802-807.

13. Horak E, Grässl G, Skladal D, Ulmer H. Lung function and symptom perception in children with asthma and their parents. Pediatr Pulmonol 2003;35(1):23-28.

14. Tosca MA, Silvestri M, Olcese R, Pistorio A, Rossi GA, Ciprandi G. Breathlessness perception assessed by visual analogue scale and lung function in children with asthma: a real-life study. Pediatr Allergy Immunol 2012;23(6):537-542.

15. Pellegrino R, Viegi G, Brusasco V, Crapo RO, Burgos F, Casaburi $\mathrm{R}$, et al. Interpretative strategies for lung function tests. Eur Respir J 2005;26(5):948-968.

16. Miller MR, Hankinson J, Brusasco V, Burgos R, Casaburi R, Coates R, et al. Standardisation of spirometry. Eur Respir J 2005;26(2):319-338.

17. Nathan RA, Sorkness CA, Kosinski M, Schatz M, Li JT, Marcus P, et al. Development of the asthma control test: a survey form assessing asthma control. J Allergy Clin Immunol 2004;113(1):59-65.

18. Dhand R, Kalra S, Malik SK. Use of visual analogue scales for assessment of the severity of asthma. Respiration 1988;54(4):255-262.

19. Zigmond AS, Snaith RP. The hospital anxiety and depression scale. Acta Psychiatr Scand 1983;67(6):361-370.

20. Herrmann C. International experiences with the hospital anxiety and depression scale: a review of validation data and clinical results. J Psychosom Res 1997;42(1):17-41.

21. Swinscow TDV. Statistics at square one, 9th edition. London: BMJ Publishing Group; 1997.

22. van der Wiel E, Postma DS, van der Molen T, Schiphof-Godart L, Ten Hacken NHT, van den Berge M. Effects of small airway dysfunction on the clinical expression of asthma: a focus on asthma symptoms and bronchial hyper-responsiveness. Allergy 2014;69(12):1681-1688.

23. Ohta K, Jean Bousquet P, Akiyama K, Adachi M, Ichinose M, Ebisawa $\mathrm{M}$, et al. Visual analog scale as a predictor of GINA-defined asthma control: the SACRA study in Japan. J Asthma 2013;50(5):514-521.

24. Leander M, Lampa E, Rask-Andersen A, Franklin K, Gislason T, Oudin A, et al. Impact of anxiety and depression on respiratory symptoms. Respir Med 2014;108(11):1594-1600.

25. Vliagoftis H. Psychological stress and asthma: a new enemy within. Int Arch Allergy Immunol 2014;164(2):109-111.

26. Katon WJ, Richardson L, Lozano P, McCauley E. The relationship of asthma and anxiety disorders. Psychosom Med 2004;66(3):349-355.

27. Roy-Byrne P, Stein M. Inspiring panic. Arch Gen Psychiatry 2001; 58(2):123-124.

28. Gorman J, Ken J, Martinez J, Browne S, Coplen J, Papp L. Psychologic changes during carbon dioxide inhalation in patients with panic disorder, major depression and premenstrual dysphoric disorders and nonill comparison group. Arch Gen Psychiatry 2002;59(2):185-186.

29. McQuaid EL, Fritz GK, Nassau JH, Lilly MK, Mansell A, Klein RB. Stress and airway resistance in children with asthma. J Psychosom Res 2000;49(4):239-245.

30. Wong KO, Hunter Rowe B, Douwes J, Senthilselvan A. Asthma and wheezing are associated with depression and anxiety: an analysis from 54 countries. Pulm Med doi: 10.1155/2013/929028.

This article is approved for Continuing Respiratory Care Education credit. For information and to obtain your CRCE

(free to AARC members) visit www.rcjournal.com

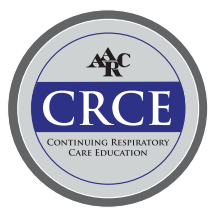

